were the only thing which could enable them to do their work.

It is not only a military but a physiolngical question of the highest interest, whether this desire for a stimulant felt by some officers ought to have been indulged. Alcohol would no doubt exert its usual effect; it would quicken the heart, and restore for the time the failing circulation; it would perhaps increase the perspiration; it would not increase, it might even slightly lessen, the temperature of the body, though so large a quantity is necessary for this that this effect cannot be reckoned upon. It might, when taken with food, increase the appetite and digestive power, and thus aid the restoration of the tissues. All this may be admitted, and when alcohol was taken within the limits of moderation (which the ration was), and in the way and at the time pointed out by Drs. Troup and Kynsey in their evidence, it can, I think, hardly be denied that it was useful to many men. But it cannot be for a moment admitted that the craving for stimulants was a proof of their necessity. The exhaustion felt on the Gold Coast was the consequence of physical conditions which nothing could alter. The effect of alcohol would have only temporarily relieved it, and, as pointed out by two witnesses, the subsequent feeling of languor would have been greater than before, and a renewed recourse to alcohol would have been necessary. The languor and exhaustion showed that the climate was not fitted for Europeans, but all we know of the physiological effects of alcohol and all the evidence of tropical service prove that under such conditions alcohol is not the remedy, but is the most faithless of helps. It could not do what is here demanded from it, and belief in it has led to innumerable deaths.

If alcohol was useful on the Coast, and I do not deny that under certain conditions it was so, it is most important that its issue should be based on the right grounds. These are shown, I think, in the evidence I have now brought forward, which has been collected impartially and without any attempt at selection. It agrees with what is known of the physiological action of alcohol, and it may truly be said that the effects stated in the foregoing evidence might have been confidently predicated.

One more remark of a practical kind may perhaps be allowed. The reviving effect produced by alcobol after great fatigue, and the power thus temporarily obtained of continuing the exertion if necessary, is a valuable quality well illustrated by some of the evidence. But this gain is only for a time, and is followed by increased exhaustion ; for, to use the common phrase, alcohol is a stimulant merely, and not a renovator, in the sense of supplying materials to exhausted tissues. This can only be done by food and rest; and as in the Ashantee campaign the men had food before or with, and rest after, the rum ration, and as the quantity of rum was within the limits of moderation, the reviving effact was felt without the subsequent depression. But no use appears to have been made in the Ashantee campaign of one of the most valuable foods for periods of great exertion which modern science has given us. I refer to the meat extracts, which also remove the sense of fatigue, but do so, in part at least, by supplying directly to the tired muscles the materials they want-viz., the special potash salts, and probably animal extractive matters, which have a reviving influence on the exhausted nerves. From their small bulk and consequent ease of carriage, their form, which permits of ready distribution, and their facility of digestion and absorption when mixed either with hot or cold water, they are at present the most available renovators we know of after great fatigue. They more than replace alcohol, or, if thought desirable, they can be used with it, and in this case will probably be found to lessen the increased depression which ensues when the effect of alcohol passes off. I have thought it not immaterial to call attention to these valuable agents which seem especially adapted for use in modern war, and which, without superseding the use of the usual food, or doing away with the necessity of rest, yet give to the modern commander additional means of increasing the marching and enduring power of his troops.

moisture in the air. On the coast the mean difference between the dry and moisture in the air. On the coast the mean difference between the dry and
wet bulb is only $2 \cdot 5^{\circ}$, and in the interior the air is often quite saturated. wet bulb is only $2 \cdot 5$, and in the interior the air is often quite saturated.
Consequently, the perspiration from the surface of the body is not carried Consequently, the perspiration from the surface of the body is not carried
off. The slightest exertion bathes the body in perspiration; this is not off. The slightest exertion bathes the body in perspiration; this is not heat of the body therefore rises, and the sense of exhaustion and fatigue produced by this condition is extreme.

\section{ON THE DISPERSION OF TUMOURS BY PUNCTURE.}

\section{BY DEPUTY INSPECTOR-GENERAL CAMERON, H.P.}

Those familiar with the East are aware that, from time immemorial, the native hakims have been accustomed to attempt to bring about the absorption of the enlargements of liver and spleen, so common in hot malarious countries, by the use of puncture with long, sharp stilets of considerable thickness. Twining, in his work "On the Diseases of Bengal," mentions the practice.

I have never followed it for the purpose of procuring the dispersion of such enlargements, but $I$ have frequently seen those of the liver disappear rapidly after repeated plunges of an ordinary hydrocele trocar when seeking unsuccessfully for suspected abscess; and I may say here, that I never saw in any instance inflammatory or any other bad symptoms produced by such operations, strange as it may appear to those unaccustomed to perform them. But what I wish to draw attention to is, that other enlargements besides those of liver and spleen may be made to disappear by puncture. Nothing is more tedious than those chronic glandular swellings which, in strumous subjects, of ten in hot countries follow upon trifling causes, such as angry mosquito bites, riding a rough bucking horse, over-exertion, or a strain in cricketing and so forth. I have seen an officer laid up for many months, and ultimately invalided with a large mass of indurated enlarged glands occupying the whole inguinal region, and resisting all the recognised routine of treatment. Accident showed me that deep puncture of such masses with a common lancet held at right angles to the swelling, and pushed down to its bottom, will of ten cause absorption to set in and proceed rapidly. The first case in which this occurred to me was one of a mercantile gentleman, disabled by a mass of swollen inguinal glands, hard as a board almost, and resisting all treatment. This patient's loss of time at office was a very serious matter to him, and, influenced by his despairing impatience, I plunged a lancet perpendicularly into the mass as far as it would reach. The point came out tinged with matter, and hard pressure brought up a little cheesy, ill-formed pus, but no discharge whatever followed, and absorption set in and proceeded rapidly.

An extraordinary and suggestive case occurred to me afterwards, which, in my opinion, affords grounds for thinking that puncture might possibly be found to bring about the dispersion of such growths as fibrous tumours of the uterus. Reasoning from the non-supervention of any evil symptoms after repeated and deep puncture of the liver, even with such a clumsy tool as a small hydrocele trocar, I see no ground for fearing to puncture with a small stilet such a fibrous uterine tumour as is of ten plainly to be felt through the abdominal parietes, and I think puncture through them less likely to be followed by any evil consequences than puncture per vaginam, owing to the perfect exclusion of air. That an analogous operation of the kind can be done safely and successfully the following remarkable case shows.

When superintending surgeon of the Southern Province in Ceylon, one of $\mathrm{my}$ assistants requested my advice respecting an infant of a few months old, whose parents were in a great state of anxiety and alarm about a swelling which they had discovered in its abdomen, and on which the usual constitutional and local treatment produced no effect. A fine healthy infant was brought forward, through whose abdominal walls a firm tumour, about the size and shape of a dove's egg, could be felt with ease. It was smooth, movable to some extent, painless on pressure, and seemed to be situated in front of the upper edge of the quadratus lumborum muscle, as far as one could judge, half way from the spine. I told the parents that nothing operative could be attempted with it, and recommended patient perseverance in the treatment already adopted, assuring them that no change was to be feared if left alone. This did not at all satisfy them; they declared the tumour was steadily increasing, and would ultimately kill their child, imploring me from time to time to save it by an operation. To all this 
I turned a deaf ear, but they worried the gentleman in charge incessantly, and at last he too begged me to do something with the case, no matter what. On seeing the child again I found that the tumour was certainly increasing, for now it was as big as a full-sized pigeon's egg ; still I counselled noninterference, assuring the parents that any operation would in all probability prove fatal. To this they replied that they were quite prepared for such a result, and willing to risk it, as death would certainly follow the steadily increasing enlargement of the tumour, so that really they had all the misery of seeing their only child dying by inches, and nothing done to prevent it! At last, like the importunate widow, they wearied me out, and as in my then position I had not to dread either Mrs. Grundy's remarks or a coroner's inquest, I agreed to "do something," at the same time distinctly stating that inflammation and death would almost certainly be the result of my meddling. Full acquiescence being given, I steadied the tumour between my fingers spread out, and then pushed a lancet, held at right angles, deep into it. The feeling communicated to the hand was that of penetrating a dense glandular structure. No trace of matter appeared on the blade, no diminution of the tumour, nor any sign of internal bæmorrhage; so the infant got a suitable opiate and a large poultice over the abdomen, the parents being quite happy at their wishes being granted. It never had the slightest fever or bad symptom of any kind, and, absorption having set in at once, the tumour, whatever it was, disappeared altogether in a very brief space, while I had the praises of my wonderful skill sounded in all directions. With this case and those where a like result followed on puncture of the liver borne in mind, I should be greatly disposed to try a similar treatment sooner than see a patient perish by hæmorrhage consequent on fibrous uterine tumour. Those who have never witnessed hepatic explorations are often very slow to believe in their safety and good effects. An old Peninsular P.M.O., new to the East, once saw me push a trocar deep into the liver three times in succession without finding the abscess I was in search of. He stole quietly away, unnoticed, while $I$ was bending over the patient, being fully convinced that death would result. Next morning he met me with a very ominous face, and inquired, "How is your man, sir P" "Oh, very well," I replied. "What, sir! very well! after re ceiving three deep punctured wounds in his liver?" I advised him to go and see for himself, and great was his surprise on doing so. In that case a perfect recovery took place, the general enlargement wholly disappeared, and the man, a sad drunkard, was soon discharged to duty.

Having, some years ago, been so well abused in the pages of this journal by the Netley Professor of Medicine, for strenuously advocating the early puncture of the liver in every case of suspected abscess, it is with peculiar pleasure that I have read in the Medical Gazette of 25th April last, p. 457 , the brilliant success of the operation at the Madras General Hospital, in a case where two distinct abscessesone containing four and the other forty ounces of pus-were opened in succession in the same patient, instead of leaving him to die of hectic while waiting for "pointing" to take place, as insisted upon by my severe critic. How many lives have I seen sacrificed to such timid practice! My long experience in such cases leaves no doubt on my mind that where hepatic abscess is suspected to exist, not a day should be lost before endeavouring to evacuate it. If this is done while the abscess is still small, and also deep-seated, I am inclined to think that nothing beyond the first emptying of it will be required, and that the canula may safely be withdrawn and the opening closed at once. The last hepatic abscess $l$ opened showed no external indications whatever of its existence. The man had never had any acute symptoms, but was steadily declining in health without any specific tangible cause, so that I was requested to see him in consultation, and diagnosed deep-seated abscess, more by the method of elimination than anything else, save the sort of intuitive conviction which long experience often causes one to feel without being able to say specifically why. I felt certain he had a deep abscess somewhere in his liver, and made two deep unsuccessful explorations for it with an ordinary trocar. Fancying I had not gone deep enough, I took a long rectum trocar, and with that hit the spot, and evacuated about two ounces of thick matter. The usual plan of fastening in the canula was adopted, but it slipped out in the night and could not be reintroduced, in conse- quence of the resistance and struggles of the man. I expected effusion into the peritoneum and death would result, but to my surprise the man rapidly recovered without the slightest bad symptom, and without any further discharge whatever, thereby considerably enlarging my ideas on the treatment of his formidable ailment; but, unfortunately, I never had another case of it during my subsequent year's service in India on which to try the improved plan of management with which accident had made me acquainted.

\section{EPILEPTIC HEMIPLEGTA.}

\author{
BY J. CRICHTON BROWNE, M.D., F.R.S.E., \\ MEDXCAL DIRECTOR, WBST RIDING ABYLUM.
}

(Concluded from p. 242.)

Ar the autopsy, which took place forty-three hours after death, the body was found to be well nourished. The skin generally, and especially that of the face, neck, and shoulders, was very sallow and swarthy. Rigor mortis was present both in arms and legs on both sides, and there was only a slight amount of hypostatic congestion. The skull, which was somewhat thickened posteriorly, was unsymmetrical and bulged a little to the left side. The bones entering into its constitution had all a bluish tinge. The dura mater presented no abnormal adhesions, but its sinuses were all much engorged with dark fluid blood. The brain entirely filled the cranial cavity, and appeared to swell out somewhat when the skull was opened. It weighed $48 \mathrm{oz}$. The arachnoid covering it was free from opacity, and the pia mater was thin and stripped freely, all its vessels, however, being distended with dark blood. It was particularly noticed that there was a good deal of congestion about the pons Varolii and medulla oblongata. The convolutions were all plump, well formed, and in close apposition. The grey and medullary substance of the hemispheres was redder than usual, and the ganglia at the base presented, on section, numerous purple stains or blotches. There was no atheroma visible, but the minute vessels seemed to have their walls somewhat thickened, and could be readily torn out of their sheaths. There was no vestige of a tumour, clot, or other local change; but a minute investigation in to the specific gravity of the different parts of the cerebrum revealed the existence of a state of what was probably fibroid induration affecting the whole brain, but the two hemispheres in a very unequal degree. The specific weights of the portions of the right hemisphere examined were, for the nost part, considerably in excess of those of corresponding portions of the left hemisphere. And the disparity between them was: actually greater than the figures representing the specific gravities, when taken alone, would indicate; for it must be borne in mind that it was established by Bastian's careful observations that the specific gravity of the grey matter, in all regions of the cerebrum, is higher on the left than on the right side. But in the brain of Mary N-, not only was the right specifically heavier than the left hemisphere, but the whole brain was specifically heavier than it would have been in a state of health. This is shown in the following table, by placing in contrast with the results obtained by its examination, the specific gravities of the different parts of the brain of a perfectly healthy man who was killed in a railway accident, and died immediately from rupture of the liver and spleen, and whose brain I was enabled to examine through the kindness of Mr. Ferguson McGill. The two brains, the specific weights of which are thus compared, were prepared and examined by precisely similar methods, and with both of them great pains were taken to arrive at accurate results. The mode of ascertaining the specific gravities was that recommended by $\mathrm{Dr}$. Sankey, the fragments of brain to be tested being immersed in adjusted solutions of sulphate of magnesia, in which barometer-makers' beads were kept floating, and no result being accepted until at least three distinct trials had been made. In the convolutions, it was the grey matter alone that was tested, small shreds of which of a determinate size and thickness were sliced from their summits, the whole brain having been previously denuded of its pia mater. A 